http://jmscr.igmpublication.org/home/ ISSN (e)-2347-176x ISSN (p) 2455-0450 crossref DOI: https://dx.doi.org/10.18535/jmscr/v8i4.88

\title{
Knowledge and practice regarding cervical cancer screening among women attending OPD of a tertiary care centre
}

\author{
Author \\ Sindhumol P K \\ Assistant Prof., CON Pune, India
}

\begin{abstract}
Cervical cancer is one of the few preventable human cancers, as long as it is detected early and managed effectively. In developing countries cervical cancer remains the most common cause of cancer related death among women. In the light of India's rapidly growing population, the overall burden of incidence and mortality of cervical cancer in India is projected to increase by $78 \%$ by the year 2030. It is unacceptable that every two minutes one women dies of cervical cancer where we have proven solutions to prevent and treat disease.93\% of the cases can be prevented if detected early through regular screening and HPV vaccination. With the objective to assess the knowledge and practice regarding cervical cancer screening, a descriptive cross sectional study was conducted among 60 women in the age group of 20 to 50 yrs attending OPD of a tertiary care centre. Structured questionnaire was administered to subjects selected by simple random sampling.50 \% of the subjects were in the age group of 31 to 40 yrs. $42 \%$ possessed good knowledge regarding cervical cancer and only 18 of them were aware about screening of cervical cancer. Practice score revealed that only 4 of them have undergone screening test. Study revealed that inspite of good knowledge practice score is negligible.

Keywords: Cervical cancer screening, knowledge, practice, HPV vaccine.
\end{abstract}

\section{Introduction}

Cervical cancer is the most preventable but the most common cancer among women in reproductive age group. In developing countries cervical cancer is a public health programme. The United Nations Global programme on cervical cancer and prevention throws light to the significance of this global issue. It is the one of the leading cause of cancer mortality, accounting for $17 \%$ of all cancer deaths among women aged between 30 and 69 years ${ }^{(1)}$. It is estimated that cervical cancer will occur in approximately 1 in 53 Indian women during their lifetime compared with 1 in 100 women in more developed regions of the world. ${ }^{(2)}$

\section{Background of Study}

India accounts for about $20 \%$ of cervical cancer cases reported from the world. ${ }^{[3)}$ More than threefourth of these patients are diagnosed in advanced stages leading to poor prospects of long term survival and cure. ${ }^{[4]}$ Early detection of cervical cancer is possible by cervical screening. It is estimated that cervical cancer will occur in approximately 1 in 53 Indian women during their lifetime compared with 1 in 100 women in more 


\section{JMSCR Vol||08||Issue||04||Page 502-504||April}

developed regions of the world ${ }^{[1]} .93 \%$ of the cases can be prevented if detected early through regular screening and HPV vaccination. Pap smear test is one of the screening test for cervical cancer.

\section{Method}

A descriptive cross sectional study was conducted on 60 subjects attended OPD of a tertiary care centre selected by simple random sampling technique. Non experimental quantitative research approach was adopted. Structured questionnaire was used to assess the knowledge regarding cervical cancer, screening of cervical cancer and practice towards cervical cancer screening.

\section{Result}

Analysis done by descriptive statistics. Majority $(50 \%)$ of the subjects belonged to age group of 31 to $40 \mathrm{yrs} 95 \%$ of the subjects were married and only $17.5 \%$ of the were employed. Only $5 \%$ were illiterate. $42 \%$ of the subjects had good knowledge 44 subjects were aware about test for cervical cancer screening. Eventhough $42 \%$ possessed good knowledge about cervical cancer and screening only 4 of them had got the screening test done.

Table 1: Sociodemographic Data

$n=60$

\begin{tabular}{|l|c|c|}
\hline Variables & Category & Number \\
\hline Age (years ) & $20-30$ & $17(30)$ \\
& $31-40$ & $30(50)$ \\
& $41-50$ & $10(12.5)$ \\
\hline Marital status & Single & $03(7.5)$ \\
\hline Educational status & Married & $7(5)$ \\
& Illiterate & $53(95)$ \\
\hline Employment status & Primary & $2(5)$ \\
& Secondary and above & $23(32.5)$ \\
\hline Religion & Employed & $17(62.5)$ \\
& Unemployed & $43(17.5)$ \\
& Hindu & $46(77.5)$ \\
\hline Type of Family & Musim & $12(20)$ \\
& Sikh & 0 \\
\hline & Christian & $02(2.1)$ \\
\hline & Nudear & $35(62.5)$ \\
& Joirt & $25(37.5)$ \\
\hline
\end{tabular}

Knowledge regarding screening for cervical cancer
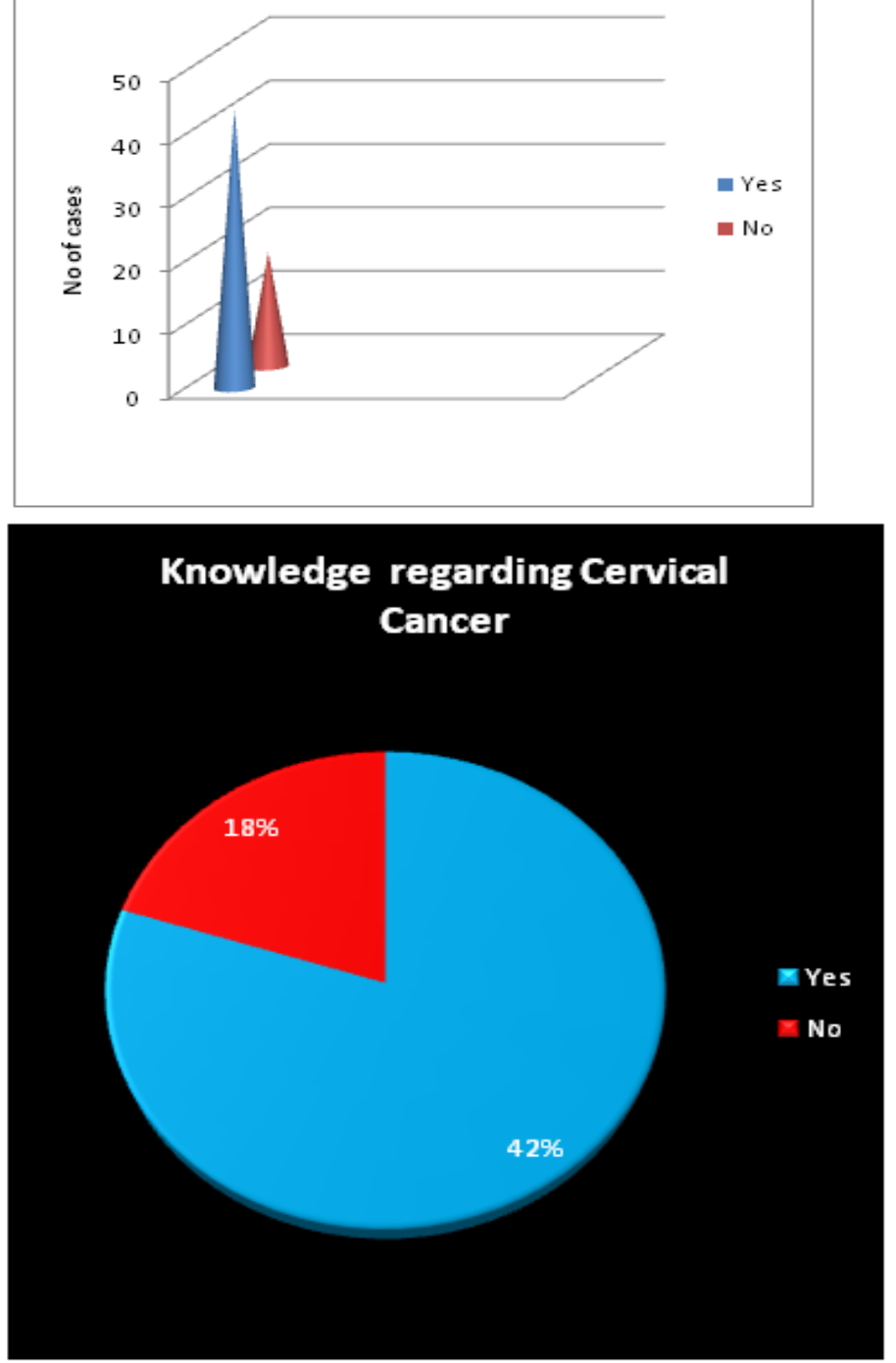

Fig 1: Knowledge score

Respondents under went PAP smear testing

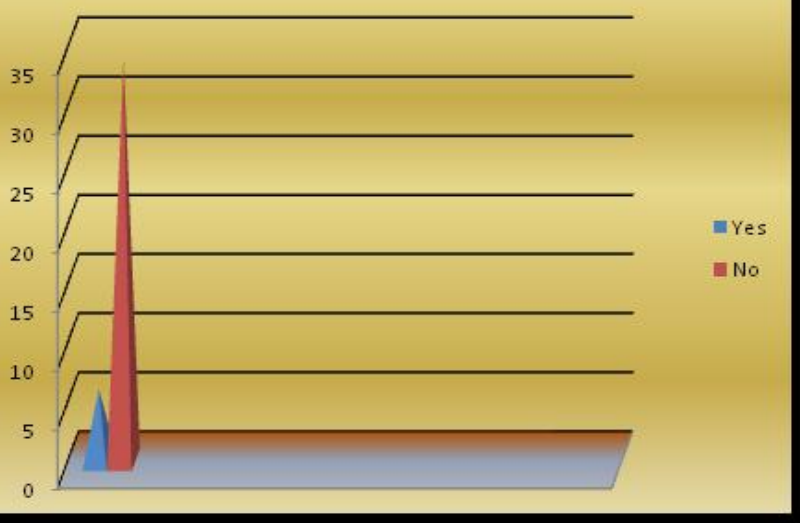

Fig 2: Practice Score 


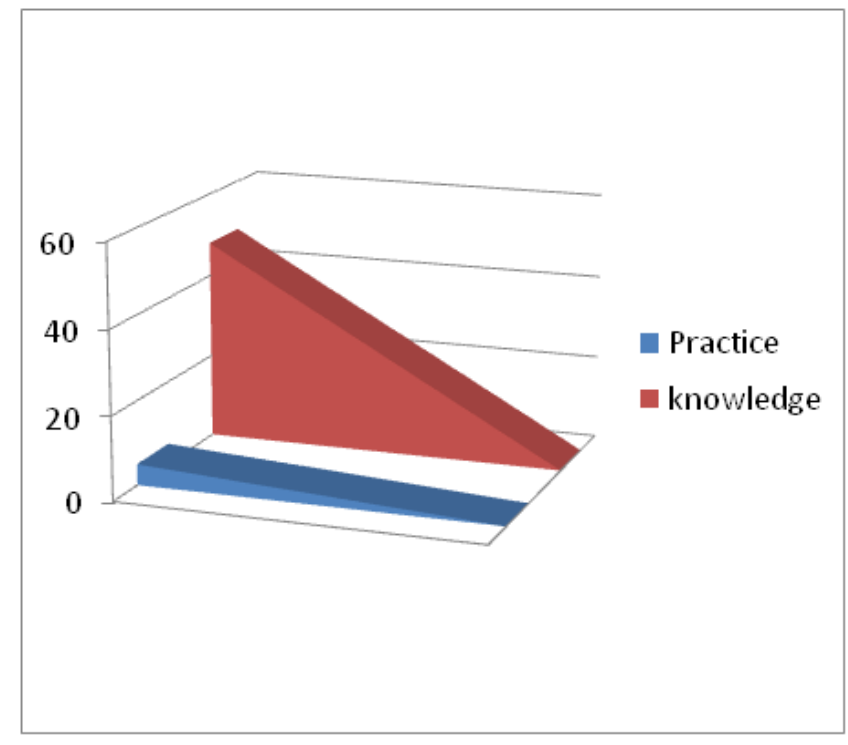

Fig 3: Comparison of knowledge and Practice score.

\section{Conclusion}

Cancer of the cervix is the third most common cancer accounting for $2 \%$ of all new cases of cancer in females with estimated 1.04 lakh cases during 2020. Cervical cancer screening is a great way of reducing the risk of cervical cancer. The study highlights the knowledge and practice regarding screening of cervical cancer among women in age group of 20-50 years attending OPD in a tertiary care centre. The study concluded that even though women have good knowledge regarding cervical cancer and its screening practice is negligible

\section{Reference}

1. HN Harsha Kumar, Shubham Tanya, A study on knowledge aand screening for cervical cancer among women in Manglore city. Journal of Ann Med Health science 2014.

2. B Saurabh, S Jignasa, J Anchal, B Ganesh, Burden of cervical cancer and role of screening in India, Indian Journal of Medical and Paediatric Oncology 2016.

3. S L Pushp, S Meenakshi, S Rekha, A study on cervical cancer screening using Pap Smear test and clinical Correlation, AsiaPacific Journal Oncology Nursing 2018.
4. Vaghela B K, Vaghela VK, Santwani PM, Analysis of abnormal cervical cytology in papanicoalaou smears at tertiary care centre.-A retrospective study, International Journal ofBiomedical and Advanced Research 2014.

5. S Rengaswamy et al, HPV screening for cervical cancer in rural India, New England Journal of Medicine, 2009.

6. P Leslea, F Donna, C Donna,W Racheal, Screening for cervical Cancer:a systemic review and metaanalysis, springer.com

7. F Fiona, Screening for cervical cancer,a review of women's attitudes, knowledge and behaviour, British Journal of General Practice, 1998. 